\title{
Problemática Laboral y Sindical 1972-1973
}

Por VICTORINO ORTEGA

A juzgar por los diagnósticos económicos oficiales, el año 1972 ha sido calificado como un año de expansión, en el que el crecimiento de la economía española alcanzó su ritmo más intenso. A este respecto se ha dado como dato significativo el aumento del producto nacional bruto en un 7,5 por 100 , mientras que el año anterior sólo alcanzó el 4,6 por 100.

Es evidente que en este crecimiento han intervenido múltiples factores. Precisamente por esto nos resulta poco inteligible leer en un mismo diagnóstico que el motor principal de este ritmo de crecimiento ha sido el trabajo, y a renglón seguido encontrarnos con que la causa principal de la expansión han sido las inversiones, que en 1972 aumentaron un 16 por 100 en términos reales. Siendo así que el crecimiento medio de las inversiones en la década de los 60 fue de sólo un 14,4 por 100. La verdad es que nos hubiera gustado conocer un reparto de premios más inteligible.

Desde el Ministerio de Industria se diagnostica que se dan todas las condiciones para que 1973 sea un año tan brillante como el que acaba de terminar, desde el punto de vista industrial. Aunque para curarse en salud se indica que la tasa de expansión puede que sea algo inferior en 1973. No obstante, se promete un crecimiento del 8 al 9 por 100 en el sector industrial.

\section{1.-Algunos datos complementarios}

Puesto que se insiste una y otra vez a nivel de objetivos que los objetivos sociales son prioritarios, es preciso aportar nuevos datos que nos describan mejor la realidad de nuestro desarrollo social. Uno de los datos que afean el cuadro económico antes diseñado es el de marcha del nivel de precios a lo largo del año 1972. 
De diciembre de 1971 al mismo mes de 1972, el incremento de los precios fue del 7,25 por 100 , al por menor, y del 6,4 por 100 , al por mayor, lo que excede del límite de la tolerancia establecida por el Plan de Desarrollo (López Rodó, en la sesión informativa de las Cortes). En términos del Plan de Desarrollo Económico y Social, esto quiere decir que ha funcionado la señal de alerta de los precios.

Con el fin de controlar los precios, el Gobierno adoptó una serie de medidas durante los meses de octubre y noviembre. Estas medidas van desde el Decreto de 9 de octubre, que regula los márgenes comerciales máximos para productos alimenticios perecederos, hasta el Decreto de 23 de noviembre de 1972, sobre regulación de las importaciones de productos alimenticios; pasando por una serie de Decretos, como el de 9 de octubre, que aumenta el poder sancionador por infracciones administrativas; el de 14 de octubre, que regula la publicidad y reitera la obligación de marcar los precios; la Orden de 3 de noviembre, que incluye en el régimen de precios máximos diversos productos de primera necesidad, y el Decreto de 15 de noviembre, que reconoce a los Gobernadores Civiles la facultad de fijar precios máximos al consumo.

A juzgar por el grado de inflación, algo menor que en 1971, es preciso reconocer que no se ha logrado atacar las verdaderas causas que la generan. $Y$ como señala sobre este punto un reciente informe de la Organización Sindical, nuestra inflación ha podido ser calificada de crónica, pues sus rebrotes aparecen últimamente tanto en los períodos de fuerte crecimiento como en aquellos otros de relativo estancamiento (1).

Otro de los datos que caracterizan, según el diagnóstico oficial, el pasado ejercicio ha sido el pleno empleo de los recursos. El paro al finalizar 1972 se ha reducido a 1,5 por 100 de la población activa. Esta cifra coincide con la que ofrecía el Servicio Nacional de Colocación en el mes de noviembre de 1972, que estimaba el desempleo en 1,54 por 100 de la población activa. Este dato es positivo, sobre todo si se tiene en cuenta que al finalizar 1971 la cifra oficial de paro involuntario era de 1,96 por 100 .

Pero también aquí es preciso referirse a otro estudio del Servicio Sindical de Estadística, en el que se nos revela que once

(1) Cfr. Informe de la Organización Sindical de 20 de diciembre de 1972.

Este informe de la Comisión Permanente señala en la pág. 20 y sigs. una serie de causas o deficiencias estructurales, que resumimos: la dimensión inadecuada de las explotaciones del sector agrario; la estructura industrial en la que coexisten empresas competitivas a nivel internacional con otras de baja productividad; el sector de distribución más dimensionado y anárquico; el sìstema fiscal, fundamentalmente basado en los impuestos indirectos (en 1971 supusieron el 65,2 por 100 del total); un elevado grado de monopolio en la fabricaclón y suministro de determinados bienes y servicios, y, por último, una desenfrenada carrera especulativa de los precios del suelo urbanizable. 
provincias, principalmente de la región andaluza y Extremadura (2), tenían al finalizar 1971 un desempleo superior al 2 por 100 . Todo ello nos indica que el fenómeno del paro sigue teniendo en España raíces muy profundas.

Comentando la distribución del paro por regiones, Luis Romasanta subraya, en base a este estudio, el hecho de que las once provincias españolas mencionadas, representando en enero de 1972 sólo un 21,2 por 100 de la población activa española, tienen que soportar nada menos que el 49,4 por 100 del paro nacional. Dicho en otros términos, que sobre una quinta parte de la población activa gravita prácticamente la mitad del paro nacional.

Entrando ya en un terreno más estrictamente laboral, nos encontramos con otros dos datos que nos introducen de lleno en la problemática que tenemos planteada en el momento actual. El número de convenios colectivos que fueron firmados en el período de enero-noviembre de 1972 alcanzó la cifra de 1.661 y afectó a una población de 3.779 .536 trabajadores.

No hay duda que el número de convenios colectivos es elevado y hasta se ha llegado a decir que ha superado en más de un 30 por 100 la contratación colectiva prevista. Posiblemente la expansión de la economía a lo largo del año 1972 ha favorecido las negociaciones. Sin embargo, la relación causal convenios colectivos-conflictos se ha mantenido estable.

El número total de conflictos colectivos que tuvieron lugar en los once primeros meses de 1972 fue de 616 , siendo así que en igual período del año anterior la cifra fue de 601 conflictos laborales colectivos. Todo esto nos indica que las situaciones conflictivas no han remitido.

\section{2.-Norma de obligado cumplimiento y negociación colectiva}

En un año de expansión económica con alto porcentaje de renovación de los convenios colectivos podía esperarse un elevado grado de conflictos laborales. Algunos encuentran la explicación del grado de estabilidad de los conflictos en las frecuentes normas de obligado cumplimiento. Más aún, en ciertos círculos se sostie. ne la tesis de que los laudos dictados por la Administración han ido en aumento en los últimos años y que, por lo tanto, la contratación colectiva viene sufriendo un deterioro.

El reciente informe sindical, antes citado, ha tratado de oponerse a esta tesis, ofreciéndonos el siguiente cuadro:

(2) Estas provincias son las siguientes: Alicante, Badajoz, Cáceres, Cádiz, Córdoba, Granada, Huelva, Jaén, Málaga, Murcia y Sevilla. El desigual reparto del desempleo en las regiones españolas es un hecho evidente. 


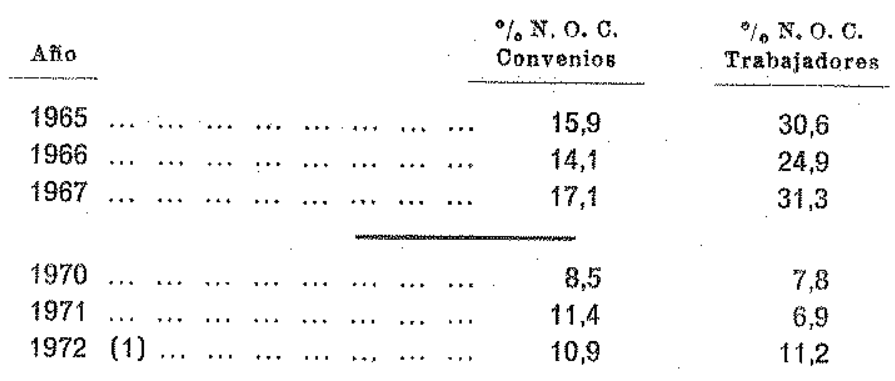

Fuente: Informe de la Organización Sindical, segundo semestre de 1972.

(i) Durante los once primeros meses.

Si damos crédito a estas cifras, es un hecho que las normas de obligado cumplimiento, en el primer año del III Plan de Desarrollo Económico y Social, han descendido en comparación con las que fueron dictadas en los años del I Plan. Sin embargo, es preciso reconocer que a partir de 1970 se advierte también un ligero aumento.

Si el porcentaje del 10 al 12 que vienen suponiendo las normas de obligado cumplimiento es normal y está dentro de los límites tolerables - como afirman las fuentes oficiales-, que todo sistema puede aceptar, éste es un juicio de valor que, sin discutirlo a fondo, sí nos atrevemos a situarlo en un contexto más amplio.

En primer lugar, la contratación colectiva durante los años 19701972, que contempla el cuadro anterior, ha estado sometida a los topes salariales del 6,5 por 100, en los convenios de un año de duración, y del 8 por 100 , en los firmados para dos o más años. Durante el año 1971 , el 50 por 100 de los convenios firmados no rebasaron estos límites. Precisamente por esto, en esta misma revista poníamos, hace un año, en duda la posibilidad de practicar. en el marco del Decreto-Ley de diciembre de 1969, una auténtica libertad de negociación colectiva (3).

En segundo lugar, creo interesa poner de relieve que la nueva normativa de conflictos colectivos data de mayo de 1970. Y entre los objetivos que se propuso cabe destacar estos dos:

- acentuar la intervención de los interesados a través de los representantes sindicales;

- tender a "que las resoluciones de trabajo se desenvuelvan por cauces propios, incluso en situaciones de anormalidad laboral, conciliando las exigencias de la buena marcha de la producción

(3) V. Ortega: Problemática laboral y sindical 1971-1972, núm, 105, pág. 31 y siguientes. 
con la libertad de las partes para hacer valer sus legitimos derechos y aspiraciones..." (4).

Si a partir de 1970 vemos que las normas de obligado cumplimiento han aumentado, quiere decir, al menos, que el último intento de regular los conflictos colectivos no ha conseguido sus principales objetivos. En este sentido se puede decir que la libertad de contratación colectiva ha sufrido un cierto deterioro.

Finalmente tenemos otro dato oficial que apoya nuestras reflexiones. Si estudiamos la relación entre normas de obligado cumplimiento y convenios en las empresas con más de 500 trabajadores, nos encontramos con estos datos.

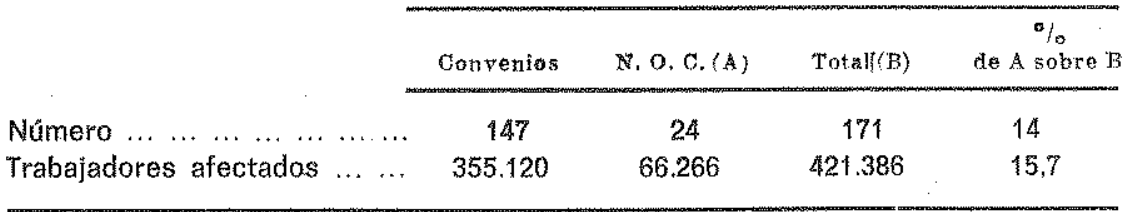

(1) Durante los once primeros meses de 1972.

A la vista de estas cifras, referidas a las empresas españolas de mayores dimensiones, y teniendo presente que la huelca sique siendo por principio ilegal, el porcentaje de un 15 por 100 de los trabajadores que se han visto afectados por las normas de obliaado cumplimiento nos parece sencillamente demasiado elevado. Más aún, dice poco en favor de una legislación todavía reciente en materia de conflictos laborales. $Y$ pone en tela de juicio la existencia real de una auténtica libertad de negociación colectiva.

\section{3.--Ni huelga ni despido libre}

Cuando apareció el Decreto-Ley de 25 de mayo de 1970 sobre regulación de los conflictos colectivos de trabajo, algunos pensaron que se trataba de una apertura de la legalidad a los paros colectivos. Es decir, que se había dado un paso hacia el reconocimiento de la huelga. En realidad, no fue así, y la experiencia de los dos últimos años ha demostrado que se ha impuesto el criterio jurisprudencial que considera todas las huelgas ilegales por principio.

En realidad, la nueva normativa de conflictos laborales se propuso afrontar las situaciones reales de "anormalidad laboral", o, lo que es lo mismo, los paros colectivos de los trabajadores, pero

(4) B. O.E de 25 de mayo de 1970. Proemio del Decreto-Ley. 
sin afrontar la regulación de la huelga. Hace exactamente un año nos hacíamos una pregunta en esta Revista: ¿La nueva Ley de Convenios y Conflictos Colectivos afrontará este problema?... "Todo hace prever-contestábamos-que no se va a dar este paso, aunque reconocemos que clarificaría mucho la situación conflictiva que estamos viviendo" (5).

Sin embargo, en el mes de octubre creímos que la nueva Ley de Convenios y Conflictos iba a afrontar el problema de la regulación de la huelga, y nos causó satisfacción. El Consejo Nacional de Trabajadores pedía que la nueva regulación de los conflictos actualice "la normativa reguladora de los conflictos colectivos, incluidos los paros producidos como consecuencia de los mismos... Creemos que la peor situación es la actual, en la que los conflictos se producen y las normas no sirven para encauzarlos o resolverlos...".

Es evidente que lo que se pedía es que se regulen "los paros" colectivos. ¿Y qué es una huelga, sino un "paro colectivo", total o parcial, producido como consecuencia o manifestación externa de un conflicto colectivo? Pero por si el contenido de la petición anterior no quedaba claro, el Consejo Nacional de Trabaiadores añade a continuación: "Los trabajadores... exigimos la existencia de la normativa necesaria, a fin de que ningún comportamiento tenga que producirse al margen de normas... Descartados los paros por razones extralaborales, la nueva normativa ha de contemplar toda situación de anormalidad, sin excluir las suspensiones de actividad laboral, a fin de que existan dispositivos aptos para hallar soluciones en las distintas situaciones que puedan plantearse" [6].

Si aquí no se pide abiertamente ya la regulación de los «paros colectivos" en el trabajo, es decir, la "huelga", quiere decir que hablamos en japonés o en chino, pero no en castellano. Alaunos Consejos provinciales de trabajadores y el mismo vicepresidente del Consejo Nacional de Trabajadores se han declarado núblicamente partidarios de regultar el derecho de huelga. Así, como sueña.

En la misma línea del Consejo Nacional de Trabajadores nos pareció que se había situado el ministro de Trabajo en su discurso del 29 de septiembre en Avila. "Necesariamente-dijo-se regulará lo tocante a los conflictos colectivos... Cuando surja un conflicto será necesario distinguir con toda claridad entre lo que es un conflicto laboral de verdad y lo que no es tal, sino un problema político. Habrá la máxima amplitud para que las partes defiendan sus intereses y se entiendan, pero no habrá cauce ni tolerancia para crear un problema político..."

(5) Cfr, V. Ortega, cit., pág. 39.

(6) Declaración conjunta del Consejo Nacional de Trabajadores, 20 de septiembre de 1972. 
La distinción entre "conflictos laborales" que se manifiestan en forma de paros, por motivos estrictamente laborales y conflictos o paros por motivos extralaborales (digamos políticos) nos pareció un buen punto de partida. Pero tal distinción no es de ahora. Desde que la Ley de 21 de diciembre modificó el art. 222 del Código Penal, existe la distinción entre la huelga con fines profesionales, que nos constituye delito, y la huelga con fines extraprofesionales, políticos en definitiva, que constituye delito de sedición.

Ahora bien, lo que nos llama la atención es que el actual ministro del Trabajo parece haber abandonado esa distinción en su discurso del 8 de enero en Barcelona. "Desde un ángulo jurídico -dijo el ministro-, el despido libre, el cierre libre de empresas, el derecho de huelga son soluciones poco jurídicas para la natural conflictividad del mundo del trabajo. Por esos caminos... Se trata en definitiva del viejo y primitivo principio de tomarse la justicia por su mano... Hemos de resistir-continuó el ministro-los em. bates de quienes, por un lado, pretenden la solución fácil del libre juego del despido o el cierre..., y la presión no menos parcial de quienes, desde otro, pretenden que la solución para conseguir las reivindicaciones laborales está en la coacción social de la huelga".

La interpretación que la opinión pública y la prensa ha dado a este discurso ha sido ésta: "Ni huelga ni despido libre". Una prueba la tenemos en el editorial del órgano de expresión de los sindicatos:

"Está claro también que la legalización de la huelga o su regulación, que había sido admitida como posible incluso por destacados dirigentes sindicales, no entra en el juego de lo futurible o previsible, como tampoco entran en este juego el despido libre o el cierre libre de la empresa" ("Pueblo", 11 de enero de 1973).

\section{4.-Binomio whuelga-despido libre", un falso planteamiento.}

Lo primero que se impone en estos momentos frente a la nueva Ley de Convenios y Conflictos Colectivos es descubrir la confusión terminológica. No se trata de despido "libre" sinónimo de "arbitrario" o "despido abusivo". Del único despido del que puede hablarse es del despido "justo" o "justificable". Y para esto lo que se necesita son unas causas de despido claramente establecidas y de acuerdo con lo que los Tribunales laborales decidan en los casos litigiosos.

El problema del "despido" no es tanto cierta corriente que trata de defender la "flexibilidad de plantillas" por modernización o reconversión de las empresas, sino el hecho de que, aun después del Decreto de 25 de mayo de 1970 , la mera participación de los 
trabajadores en los paros colectivos (huelgas) les hace acreedores de la sanción del despido (7).

Cuando se pide la reglamentación o regulación de la huelga, nadie está pensando en la "libertad de huelga" a secas, en lo que el presidente del Consejo Nacional de Empresarios llama "la vuelta al primitivismo", ni al principio de "tomarse la justicia por su mano". Para esta misión están los Tribunales.

El problema planteado no es otro que el de abrir cauce legal a las realidades conflictivo-faborales tal y como se manifiestan. Veamos los hechos. Durante los once primeros meses de 1972 se produjeron 616 conflictos laborales-cifra más alta que en 1971-, lo que supone casi un 40 por 100 , en relación con el número de convenios colectivos firmados. La norma de obligado cumplimiento, como hemos señalado antes, ha supuesto un 10 ó 12 por 100 , en relación con los convenios colectivos firmados. Más aún, viene siendo una constante en los últimos años que la conducta adoptada por los trabajadores, en el 90 por 100 de los conflictos laborales es la de paro total o parcial en el trabajo. De lo que se trata es de regular o reglamentar estos paros colectivos. Es decir, estas huelgas.

No ignoramos que en muchos conflictos las motivaciones o causas que los originan puedan ser extralaborales. Pero tanto los informes de la Secretaría Técnica del Ministerio de Trabajo como el ya citado de la Comisión Permanente del Congreso Sindical (8) muestran que predominan en los conflictos colectivos las motivaciones laborales.

Abundando en este sentido, tenemos un escrito que sólo se ha hecho público en la siguiente nota de prensa:

"Seiscientos trabajadores de Vigo han elevado un escrito a los ministros de Justicia y Trabajo, en relación con la situación derím vada del paro laboral del mes de septiembre último. Señalan que el conflicto respondió a un malestar creciente, debido a los bajos salarios, desempleo y emigración, y con respecto a la situación de los despedidos, dicen que en los posibles casos en que los despidos fueron declaros improcedentes por la Magistratura de Trabajo, la mayor parte de los afectados no consiguieron la readmisión" ("Informaciones", 10 de enero de 1973).

El problema, pues, visto desde la justicia social, no es sólo el caso aquí descrito de la no readmisión de los despedidos "improcedentemente" por la empresa. Paradójicamente, después de hacer justicia la Magistratura, declarando "improcedente" el despido, es

(7) Cfr. T. S., 29 de noviembre de 1971. En idéntico sentido véanse las dos sentencias del Tribunal Central de Trabajo de 6 y 13 de noviembre, respectivamente.

(8) Véase nota 1. 
la empresa la que decide entre readmitir o indemnizar. Aunque la opción en estos casos le corresponda al trabajador-cosa que difícilmente se va a lograr-quedará el problema sin resolver de que por el hecho de adoptar una conducta de paro, los trabajadores se sitúan en la ilegalidad $y$, por consiguiente, son despedidos o pueden serlo.

En esta situación de evidente inferioridad legal de los trabajadores, defender la tesis de la huelga, de su reglamentación, a cambio de mayor libertad de despido, es un falso planteamiento. $Y$ en este truco parecen haber caído ahora quienes autorizadamente dicen: "No a la huelga, no al despido "libre" ". Caer en esta dialéctica en el momento de actualizar la legislación sobre conflictos colectivos laborales nos parece un error, si no es una ingenuidad.

\section{5.-Huelgaulocknout) (cierre empresarial).}

Si hay una contrapartida al derecho de huelga y a su regulación, es el llamado "lock-out" o cierre de la empresa. Y esto es así tanto en la evolución histórica de los conflictos colectivos como en la doctrina, legislación o jurisprudencia laboral. Por eso, el binomio huel. ga-cierre empresarial es el único planteamiento serio que merece estudiarse. La huelga puede ser un simple derecho social o puede, incluso, ser elevado a la categoría de derechos garantizados por la constitución.

Los paros colectivos en el trabajo o huelgas suponen las asociaciones sindicales de los trabajadores, digamos el derecho de fundar asociaciones para la defensa de los intereses de las clases trabajadoras, y su fundamento está en la libertad que tiene todo hombre de trabajar o de cesar en el trabajo por motivos razonables y justificados. El "lock-out" o cierre de las empresas no precisa siempre del derecho de coalición y asociación de los empresarios, sino que es una consecuencia, una derivación natural, del derecho de propiedad.

Uno y otro derecho han pasado por distintas etapas: de prohibición, de tolerancia y de reconocimiento legal. En el momento actual, en España, la huelga sigue en teoría en la etapa de prohibición, sigue siendo ilegal por principio; pero la huelga por motivos estrictamente laborales no constituye delito después de la reforma del artículo 222 del Código Penal. Sociológicamente hablando, diríase que nos encontramos en una etapa de tolerancia, desde el momento que la inmensa mayoría de los trabajadores que participan en los paros colectivos, es decir, en los conflictos exteriorizados al margen de los cauces legales, vuelven a ser admitidos... Lo que ahora habría que hacer es dar un paso más hacia la etapa de reconocimiento reglamentado de los paros laborales por motivos justificados. 
No hay duda que existe una especie de contradicción entre la normativa legal sobre conflictos colectivos y la realidad conflictivo. laboral. Hoy estamos convencidos de que en España existen y existirán conflictos colectivos que adoptan la forma externa de paros en el trabajo, es decir, auténticas huelgas. $Y$ creemos que precisamente por esto se admite-es legal-el "lock-out" o cierre de las empresas desde 1970. Naturalmente los cierres sólo se admiten excepcionalmente: para prevenir daños inminentes; b) para evitar la ocupación del centro de trabajo, y c) por la inasistencia reiterada del personal que impida el proceso normal de producción. Está claro que se reconoce, excepcionalmente repetimos, en la actual legislación el "cierre" de las empresas, como contrapartida de los paros o huelgas que se dan y se prevé que se seguirán dando. ¿Por qué no regular la huelga excepcionalmente y así evitar esta contradicción o desigualdad legal entre empresas y trabajadores? Aquí esta el problema, todavía no resuelto.

Analicemos ahora las razones que se dan para no regular la huelga. Se dice que el reconocimiento de la huelga es una "vuelta al primitivismo", al viejo principio de "tomarse la justicia por su mano". "Hoy - ha dicho el presidente del Consejo Nacional de Empresarios-tenemos en España cauces jurídicos para encontrar soluciones. Y lo que hay que hacer no es regular la huelga, sino evitar que ésta se produzca, utilizando los máximos instrumentos de arbitraje dentro de la Organización Sindical" (9).

Nos cuesta creer que la regulación de la huelga en los países europeos haya sido una "vuelta al primitivismo". Ni que la justicia laboral se haga en Europa por la huelga, sin tribunales de justicia. Cuando se habla así, se está hablando de algo que no tiene nada que ver con un derecho social, sino de la ley de la selva. Y no es este nuestro caso. Nadie niega que existen cauces jurídicos sindicales en España y que deben ser utilizados al máximo. El problema se plantea cuando la conciliación, mediación o arbitraje fallan. Entonces, ¿qué sucede? Pues que el conflicto colectivo se manifiesta externamente en formas de paro total o parcial, es decir, en forma de huelga. Lo que automáticamente sitúa a los trabajadores en la ilegalidad.

Una cosa está clara: la opinión del Sr. Conde Bandrés, en lo que tenga de representativa del Consejo Nacional de Empresarios-coco presidente--, es opuesta a la antes citada del vicepresidente del Consejo Nacional de Trabajadores, que se mostró partidario de regular la huelga.

El Sr. Conde Bandrés opina que "la huelga no es rentable para nadie", pero no es ésta la cuestión planteada, sino otra muy distinta: ¿para quién es más rentable la prohibición absoluta de la huelga? En una economía de mercado los conflictos de intereses

(9) Cfr. Entrevista a D. Manuel Conde Bandrés, en Pueblo, 27-1-1973. 
terminan fácilmente en paros huelguísticos. Y la cuestión es saber si los inconvenientes que se seguirian de la regulación de la huelga son mayores de los que se siguen de la prohibición absoluta en la situación actual.

Desde el punto de vista ético-moral sabemos que «la huelga puede seguir siendo medio necesario, aunque extremo, para la defensa de los derechos y el logro de las aspiraciones justas de los trabajadores" (10). Este criterio moral choca ciertamente con los criterios expuestos antes y que tratan de imponerse por'otros motivos que no se exponen abiertamente.

Finalmente, se ha dado otra razón para impedir la regulación de la huelga. A saber: que tales planteamientos entran "en contradicción con los principios esenciales de nuestro sistema, con el concepto mismo de nuestro sindicalismo y con el Estado de derecho establecido por el Régimen".

Sin entrar a fondo en esta argumentación, no es éste el momento, si quiero decir que esto está por demostrar científicamente. Que tal argumentación es de marcado carácter político. Que puede ser válida respecto de las huelgas "salvajes", las huelgas políticas o por motivos extralaborales, pero no lo es por lo que se refiere a los paros colectivos por motivos estrictamente laborales, que en la actualidad son la mayoría. Y la razón es la siguiente: en estos casos no se "perturba gravemente la producción nacional" (Declaración XI del Fuero del Trabajo), ni equivalen por principio o por definición a desorden público. En todo caso el problema que plantea la contradicción entre reconocimiento de la huelga y el Estado de Derecho establecido por el Régimen-según se afirma apriorísticamente-tendrán que abordarlo las Cortes al discutir el proyecto de Ley sobre conflictos colectivos. Sólo deseamos que se acierte con la solución más de acuerdo con la opinión pública de toda la población trabajadora, y, sobre todo, con la justicia social.

\section{6.-La realidad sindical.}

El año 1972 terminó sin que se haya culminado la etapa de desarrollo normativo reglamentario que prevé y exige la nueva Ley Sindical. Han pasado casi dos años desde que la Ley Sindical fue aprobada en las Cortes. Merecen citarse por su importancia dos medidas de desarrollo de la Ley Sindical. Se trata del decreto de 9 de noviembre de 1972 sobre organizaciones profesionales sindicales, y el Decreto que regula la sindicación y sus efectos, aprobado el 27 de enero de 1973 en Consejo de ministros.

El primero de estos Decretos tiene por objetivo dos cosas: a) regular las organizaciones profesionales que han surgido a lo largo de

(10) Texto del Vaticano H ( G. S.", 68). 
treinta años con diferentes denominaciones, y b), regular la creación de otras nuevas, es decir, las "asociaciones sindicales" voluntaria y libremente constituidas.

El primero de estos dos objetivos creemos que sí se consigue. El segundo de los objetivos está por ver. Las asociaciones volun" tarias y libres no pueden crearse por Decreto. Dependerán de la opción que hagan los trabajadores desde la base de sus aspiraciones. Como el Decreto respecto del nacimiento de estas asociaciones mantiene los mismos criterios que fueron fijados en la Ley Sindical, la respuesta que den los trabajadores a la norma legal con su comportamiento será el mejor "test" para ver si las Cortes en su día acertaron o no a establecer el orden jurídico y las garantías suficientes que requiere el ejercicio de la libertad sindical.

Uno de los derechos que fueron regulados por el Decreto de 30 de abril de 1971, es el derecho de reunión de los sindicados. Sobre el interés que prestan los trabajadores y los empresarios al ejercicio del derecho de reunión tenemos unos datos oficiales que no requieren comentario.

En el período de cuatro meses (1 de julio-31 de octubre de 1972) se celebraron 151 reuniones en total, en las que participaron 17.003 sindicados, distribuidos de la siguiente forma:

- 115 reuniones de trabajadores, con 14.789 participantes, y

- 36 reuniones de empresarios, con 2.214 asistentes.

Si estos datos muestran un grado elevado de interés por el derecho de reunión o muy escaso, juzgue el propio lector. Puede servir de elemento de juicio saber que en la provincia de Madrid hubo 44 reuniones durante ese período de cuatro meses, en las que sólo participaron 3.503 trabajadores y 620 empresarios (11).

Está a punto de convocarse el V Congreso Sindical, que, en principio, se piensa celebrar en Madrid. $Y$ entre los puntos o temas que estudiará está, sin duda, la nueva regulación de convenios y conflictos. Es muy posible que al abordar este tema las dos posiciones antes expuestas, la una representada por el presidente del Consejo Nacional de Empresarios, que sigue diciendo no a la regulación de la huelga, y la otra representada por el vicepresidente del Consejo Nacional de Trabajadores, que pidió la regulación de la huelga, vuelvan a plantearse.

Lo peor que puede ocurrir es que siga el planteamiento confuso del binomio huelga-despido libre. Si no se rompe este círculo vicioso, la reforma de los conflictos colectivos no irá más allá de la del Decreto de 25 de mayo de 1970, lo que sería muy de lamentar.

(11) Cfr. Informe Sindical citado en nota 1, págs. 28 y sigs. 